\title{
Use of LMA for awake intubation for Caesarean section
} Mark Godley MB CHB, A.R. Ramachandra Reddy BSC MBBS DA FRCPC

Purpose: This case report describes the use of a Laryngeal Mask Airway in a morbidly obese parturient with the H.E.L.L.P. syndrome. An urgent Caesarean section was required because of vaginal bleeding and fetal distress.

Clinical features: The patient was a 32 year old G3, T1, PI, $L 1$ who presented with epigastric pain, headache, vomiting, and diarrhoea. She was hypertensive $(180 / 110 \mathrm{mmHg})$ and thrombocytopaenic $\left(18 \times 10^{-9} \cdot \mathrm{L}^{-1}\right)$. Examination of the airway revealed a short neck, receded jaw, full dentition, large breasts and she was considered to be a potential intubation problem. The patient required an awake intubation using $a$ technique that minimized hypertension, aspiration risk, airway trauma, and hypoxia. A laryngeal mask was used to facilitate tracheal intubation, and the patient tolerated the procedure with no adverse outcome.

Conclusion: The LMA has a place to facilitate potentially difficult awake tracheal intubation with the pregnant patient.

Objectif: Cette observation décrit l'usage du masque laryngé (ML) chez une patiente obèse souffrant du syndrome HELLP. Une césarienne était devenue urgente à cause d'un saignement vaginal et d'une détresse foetale.

Caractéristiques cliniques: La patiente était âgée de 32 ans et présentait une douleur épigastrique, de la céphalée, des vomissements et de la diarrhée. Elle était de plus hypertendue $(180 / 110)$ et thrombocytopénique $\left(18 \times 10^{-9} \cdot L^{-1}\right)$. L'examen des voies aériennes a révélé un cou court, une mâchoire fuyante, une denture complète et des seins volumineux, ce qui permettait d'anticiper une intubation difficile. A cause de ces éléments, une intubation vigile était indiquée avec une tech-

\section{Key words}

ANAESTHESIA: obstetric;

ANAESTHETIC TECHNIQUE: awake intubation;

EQUIPMENT: laryngeal mask airway;

OBSTETRICS: HELLP syndrome, morbid obesity.

From the Department of Anaesthesia, University of British Columbia, B.C. Women's Hospital and Health Centre Society, 4490 Oak Street, Vancouver, British Columbia, V6H 3 V5.

Address correspondence to: Dr. A.R.R. Reddy, 1270 Wolfe Avenue, Vancouver, BC, V6H 1 W1.

Accepted for publication 27th October, 1995. nique capable de minimiser l'hypertension, le risque d'aspiration, les traumatismes des voies respiratoires et l'hypoxie. Un masque laryngé a servi à faciliter l'intubation de la trachée et la patiente a toléré la manoeuvre sans complications.

Conclusion: Le ML a sa place comme aide a l'intubation vigile des voies aériennes difficiles chez la femme enceinte.

The Laryngeal Mask Airway (LMA) was developed as an artificial airway for routine general anaesthesia. However, it has a role in management of the difficult airway and as an aid to blind and fibreoptic intubation for both elective and emergency situations. ${ }^{1}$ We describe its use in a patient with morbid obesity complicated by pregnancy-induced hypertension (RIH) and a haemolysis, elevated liver enzymes, low platelets (HELLP) syndrome. It served to protect the oropharynx from possible soft tissue injury during awake intubation and allowed easy control of a difficult airway.

\section{Case report}

A 32-yr-old G3, T1, P1, L1 patient was admitted at 31 wk gestation with a six day history of epigastric pain, vomiting and diarrhoea and recent onset of severe backache. She was hypertensive $(180 / 110 \mathrm{mmHg})$ and appropriately oriented. The only recorded weight was $105 \mathrm{~kg}$ (pre-pregnant) and she was estimated to be 162 $\mathrm{cm}$ tall (body mass index 40 ). She had gross facial oedema and oedema of the arms, legs and abdomen. She was not distressed in the semi-sitting position. Her antenatal care had been uneventful. There was no past history of hypertension, connective tissue disorders or renal disease. She reported having an uneventful general anaesthetic as a child and there were no known allergies to medication. Examination revealed a Mallampati class 3 airway. Her teeth were prominent, there was reduced flexion/extension of her neck and she had large breasts. She had equal breath sounds bilaterally with some crepitations at both lung bases. Precordial auscultation was normal. Reflexes were brisk with no clonus. Abdominal examination revealed a mildly tender right upper quadrant. Arterial blood gases had not been done. Oxyhaemoglobin saturation was $92 \%$ with oxygen supplementation by face mask $\left(\mathrm{FIO}_{2}=1.0\right)$. 
Urine output was $>100 \mathrm{ml} \cdot \mathrm{hr}^{-1}$ and there was $3+$ proteinurea and moderate occult blood. Coagulation parameters were an international normalized ratio (INR) of 0.97 , activated partial thromboplastin time (APTT) of $27.8 \mathrm{sec}$, PT $11.8 \mathrm{sec}$, fibrinogren $3.90 \mathrm{~g} \cdot \mathrm{L}^{-1}$ and platelet count of $25+10^{-9} \cdot \mathrm{L}^{-1}$, and the haemoglobin concentration was $111 \mathrm{~g} \cdot \mathrm{L}^{-1}$. A diagnosis of PIH complicated by HELLP syndrome was made.

Treatment included magnesium sulfate at $2 \mathrm{~g} \cdot \mathrm{hr}^{-1} i v$, intermittent sublingual nifedipine $10 \mathrm{mg}$, and methyldopa $500 \mathrm{mg} \mathrm{q} 6 \mathrm{~h}$, and oral ranitidine $150 \mathrm{mg} \mathrm{q} 8 \mathrm{hr}$ po. A left radial arterial catheter was inserted and measured blood pressures between $170 / 98 \mathrm{mmHg}$ and 190/110 $\mathrm{mmHg}$ with a regular heart rate of $75 \mathrm{bpm}$. Cardiotocography revealed no fetal distress. Induction and augmentation of labour were commenced with an oxytocin infusion and a foley catheter was used to dilate the cervix. Anaesthesia was consulted in case induction of spontaneous labour was unsuccessful. The BP was $200 / 110 \mathrm{mmHg}$ with a regular heart rate of $98 \cdot \mathrm{min}^{-1}$. Her haemoglobin concentration had decreased to 96 $\mathrm{g} \cdot \mathrm{L}^{-1}$, platelets to $10 \times 10^{-9} \cdot \mathrm{L}^{-1}$ (over $12 \mathrm{hr}$ ), and her liver enzymes were abnormal: serum aspartate aminotransferase $277 \mathrm{U} \cdot \mathrm{L}^{-1}$, lactate dehydrogenase 3105 $\mathrm{U} \cdot \mathrm{L}^{-1}$, albumin $31 \mathrm{~g} \cdot \mathrm{L}^{-1}$. A peripheral blood smear showed fragments, spherocytes and large platelets.

Progress of labour was poor. The Foley catheter became dislodged, the cervix failed to dilate, and the presenting parts remained high. Twelve hours after admission, the patient developed an antepartum haemorrhage and required urgent Caesarean section. She developed bleeding from intravenous sites, gums and lips, although the INR, APTT, and fibrinogen remained unchanged. At this stage, a haematologist suggested infusing three units of fresh frozen plasma and five units of platelets before surgery. This increased her platelet count to $39 \times 10^{-9} \cdot \mathrm{L}^{-1}$, with a haemoglobin concentration of $96 \mathrm{~g} \cdot \mathrm{L}^{-1}$. Arterial blood gas prior to induction of anaesthesia showed $\mathrm{pH}$ of $7.47, \mathrm{PCO}_{2} 30 \mathrm{mmHg}, \mathrm{PO}_{2}$ $92 \mathrm{mmHg}, \mathrm{HCO}_{3} 22, \mathrm{BE}-0.1\left(5 \mathrm{~L} \cdot \mathrm{min}^{-1} . \mathrm{O}_{2}\right.$ by nasal prongs.) There were no signs of fetal distress and she remained haemodynamically stable.

\section{Anaesthetic management}

The anaesthetic approach was discussed with the patient. She continued to receive magnesium sulfate at $2 \mathrm{~g} \cdot \mathrm{hr}^{-1}$ iv and had taken ranitidine $150 \mathrm{mg}$ po. She had been fasting since her admission to the labour room. She was given $30 \mathrm{ml}$ sodium citrate $30 \mathrm{~min}$ before induction of anaesthesia, as she had stopped vomiting. All monitors were placed according to CAS guidelines. Five millilitres lidocaine $4 \%$ were nebulized by face mask. With the patient in the supine position and with left uterine displacement a \#4 LMA was inserted easily with no discomfort to the patient. Blood pressure was 170/105 $\mathrm{mmHg}$ and oxyhaemoglobin saturation was $95 \%$. Oxygen was administered through the circle system with the patient breathing spontaneously. A fibreoptic laryngoscope was inserted through the LMA revealing a clear view of the vocal cords and was then removed. ${ }^{2,3}$ Subsequently, $2 \mathrm{ml}$ lidocaine $4 \%$ were sprayed through the LMA producing some coughing. At this time, $100 \mu \mathrm{g}$ fentanyl were given, facilitating a haemodynamically smooth (BP 175/95 $\mathrm{mmHg}$ ), blind insertion of a \#6 cuffed tracheal tube (TT) through the LMA with the circle circuit disconnected. Connecting the circle circuit allowed easy oxygenation and spontaneous ventilation. Capnography confirmed the correct placement of the TT. After securing the airway, the fetal heart rate was unobtainable by abdominal ultrasound. Expeditious delivery of the fetus was necessary. Anaesthesia was induced with propofol $120 \mathrm{mg}$ and muscle relaxation was achieved with $4 \mathrm{mg} i v$. An additional $100 \mu \mathrm{g}$ fentanyl were given for analgesia. Anaesthesia was maintained with isoflurane $0.5 \%$, nitrous oxide $50 \%$ in oxygen.

The patient was haemodynamically stable, but did require labetalol on two occasions (totaling $20 \mathrm{mg}$ ) to control hypertension. There was considerable blood loss at the time of delivery and hypovolaemia was rapidly treated with two units of packed red blood cells and two units of fresh frozen plasma. An infant girl weighing $1295 \mathrm{~g}$ (cord $\mathrm{pH} 7.33$ ), with Apgar scores of 7 and 9 was delivered. Oxytocin $30 \mathrm{U}$ in one litre of normal saline was infused for poor uterine contraction. To facilitate uterine contraction prostaglandin F2alpha $(140 \mu \mathrm{g})$ was injected directly into the myometrium. Palpation of the liver prior to abdominal closure was normal. The patient remained haemodynamically stable.

At the conclusion of the operation, a \#8.5 Fr right internal jugular line was placed before transfer to the intensive care unit. The LMA and tracheal tube were removed as the neck anatomy was distorted by the LMA. Using a gum elastic bougie and cricoid pressure, the tracheal tube and laryngeal mask were removed and a \#7 tracheal tube was railroaded over the bougie. The central line was then inserted without difficulty.

At the end of surgery, with adequate ventilation $\left(\mathrm{PETCO}_{2}<40 \mathrm{mmHg} \mathrm{SPO} \mathrm{SP}_{2}>95 \%\right.$ breathing $\mathrm{FIO}_{2} 1.0$ ), the trachea was extubated and she was fully conscious. She was subsequently transferred to an ICU for postoperative management.

\section{Discussion}

The HELLP syndrome describes a subset of patients 
with pregnancy induced hypertension who present preterm, frequently requiring Caesarean section for fetal and/or maternal reasons. ${ }^{4}$ In this patient, general anaesthesia was necessary because thrombocytopaenia contraindicated regional anaesthesia. Correction of thrombocytopaenia by transfusion might have predisposed to a thrombotic event. ${ }^{5}$ Even after platelet transfusion the platelet count was considered to be too low to contemplate regional anaesthesia.

One of the major causes of maternal mortality related to anaesthesia in obstetrics is difficult or failed tracheal intubation. ${ }^{6}$ In addition, obesity is associated with difficult intubation with increasing morbidity in the obstetric population. ${ }^{7}$ Furthermore, HELLP syndrome has been associated with laryngeal oedema which also has been associated with perioperative mortality. ${ }^{8}$ In this case, we were concerned that airway management would be difficult. Had general anaesthesia been induced before securing the airway, we might have been faced with a "can't intubate, can't ventilate" scenario.

The combination of pregnancy induced hypertension and thrombocytopaenia require tracheal intubation to be atraumatic and haemodynamically stable. Our patient was hypertensive and had a potentially difficult airway with clinical evidence of coagulopathy. To overcome these difficulties, an awake controlled atraumatic intubation was performed with the aid of an LMA after topical anaesthesia of the airway with nebulized lidocaine.

With conventional fibreoptic intubation, it may be difficult to advance the tracheal tube over the bronchoscope in 80 to $90 \%$ of cases, because it impacts upon the epiglottis, right arytenoid or hypopharynx despite the successful insertion of the fibrescope into the trachea. ${ }^{9}$ Impact upon these structures in this patient may have produced trauma and bleeding but this problem was overcome by using the LMA.

Fibreoptic intubation through the LMA has been described in non-pregnant patients. ${ }^{10} \mathrm{We}$ used the fibreoptic laryngoscope to assess the position of the laryngeal mask and, in addition, to assess the glottis. The adjuvant use of fentanyl iv facilitated the smooth induction and maintenance of haemodynamic stability, although we were aware of the risk to the fetus. However, labetalol was required on two occasions before delivery to control hypertension.

This report indicates another possible use for the LMA. Its soft, blunt surface was well tolerated by the awake patient with a topically-anaesthetized upper airway. It also served to protect against soft tissue injury during fibreoptic assessment of the larynx and tracheal tube insertion. The teeth are unlikely to be damaged as there is no need to use a laryngoscope. Fibreoptic assessment is important as it confirms good positioning of the laryngeal mask before tracheal intubation. Blind insertion of the tracheal tube may fail if the position of the LMA has not been confirmed. "

The urgency to proceed with surgery prevented us from inserting a central line until late in the procedure. Other access sites such as the antecubital fossa were not considered and may have been a better choice since thrombocytopaenia may predispose to haemorrhage and haematoma. At this time, it was noted that the LMA distorted the anatomy of the neck, making insertion of a central line difficult. A gum elastic bougie was used to change the TT and remove the LMA. This technique has been investigated previously with a reported success rate of $84-88 \% .^{10} \mathrm{~A}$ hollow tube changer may also be used to aid TT insertion, the tracheal position of which can be confirmed by end tidal $\mathrm{CO}_{2}$ monitoring while sampling through the tube changer.

\section{Conclusion}

This case report illustrates the use of the LMA in the obstetric patient where failed intubation is more prevalent than in the general population. ${ }^{12}$ Visualization with a fibreoptic bronchoscope is important to eliminate any obstruction by the epiglottis before blind intubation through the LMA is attempted. The TT will facilitate long-term ventilation if necessary and protect the airway from regurgitation and aspiration. The LMA has a useful place for obstetric patients, but anaesthetists should be familiar with its use and with the fibreoptic bronchoscope before using it in emergency situations. In addition, insertion of the central line before using the LMA should be kept in mind, as distortion of the local anatomy will interfere with insertion later.

\section{Acknowledgements}

The authors are grateful to Dr. Sanjay Datta, Brigham and Women's Hospital, Boston, for his assistance and suggestions with the preparation of this manuscript.

\section{References}

1 Pennant JH, White PF. The laryngeal mask airway. Its uses in anesthesiology. Anesthesiology 1993; 79: 144-63.

2 Benumof $J L$. Use of the laryngeal mask airway to facilitate fiberscope-aided tracheal intubation (Letter). Anesth Analg 1992; 74: 313-4.

3 Smith JE, Sherwood NA. Combined use of laryngeal mask airway and fibreoptic laryngoscope in difficult intubation (Letter). Anaesth Intensive Care 1991; 19: 471-2.

4 Sibai BM, Ramadan MK, Usta I, Salama M, Mercer BM, Friedman $S A$. Maternal morbidity and mortality in 442 pregnancies with hemolysis, elevated liver enzymes, and 
low platelets (HELLP syndrome). Am J Obst Gynecol 1993; 169: 1000-6.

5 Gordon $L I$, Kwaan $H C$, Rossi EC. Deleterious effects of platelet transfusions and recovery thrombocytosis in patients with thrombotic microangiopathy. Seminars in Hematology 1987; 24: 194-201.

6 Davies JM, Weeks S, Crone LA, Pavlin E. Difficult intubation in the parturient. Can J Anaesth 1989; 36: 668-74.

7 Hood DD, Dewan DM. Anesthetic and obstetric outcome in morbidly obese parturients. Anesthesiology 1993; 79 : 1210-8.

8 Rocke $D A$, Scoones $G P$. Rapidly progressive laryngeal oedema associated with pregnancy-aggravated hypertension. Anaesthesia 1992; 47: 141-3.

9 Asai $T$, Morris $S$. The laryngeal mask airway: its features, effects and role. Can J Anaesth 1994; 41: 930-60.

10 McNamee CJ, Meyns B, Pagliero KM. Flexible bronchoscopy via the laryngeal mask: a new technique. Thorax 1991; 46: 141-2.

11 Allison A, McCrory J. Tracheal placement of a gum elastic bougie using the laryngeal mask airway (Letter).

Anaesthesia 1990; 45: 419-20.

12 Endler GC, Mariona FG, Sokol RJ, Stevenson LB. Anesthesia-related maternal mortality in Michigan, 1972 to 1984 . Am J Obstet Gynecol 1988; 159; 187-93. 